\title{
Differences in feeding ecology predict differences in performance between golden lion tamarins (Leontopithecus rosalia) and Wied's marmosets (Callithrix kuhli) on spatial and visual memory tasks
}

\author{
MICHAEL L. PLATT \\ University of Pennsylvania, Philadelphia, Pennsylvania \\ ELIZABETH M. BRANNON \\ Columbia University, New York, New York \\ and \\ TARA L. BRIESE and JEFFREY A. FRENCH \\ University of Nebraska, Omaha, Nebraska
}

\begin{abstract}
Golden lion tamarins (Leontopithecus rosalia) and Wied's marmosets (Callithrix kuhli) exhibited adaptive differences in performance on several distinct memory tasks. On both an open-field analogue of a radial arm maze and a spatial delayed matching-to-sample task, the marmosets performed better than the tamarins after short (5-min) retention intervals, but only the tamarins continued to perform above chance after long (24- or 48-h) retention intervals. The marmosets also required less training than the tamarins did to learn a color memory task, but again only the tamarins performed above chance when the retention interval was increased to $24 \mathrm{~h}$. The results of these experiments are consistent with predictions based on knowledge of the feeding ecology of these species in the wild and raise the possibility that they possess different visuospatial memory abilities specialized for tracking the spatial and temporal distribution of their principal foods.
\end{abstract}

Recent evidence from birds and rodents suggests that species that perform spatially demanding behaviors, such as recovering seeds from thousands of dispersed caches or navigating large and complex home ranges, often display enhanced abilities in spatial learning and memory tests. Among birds of the food-caching family Corvidae, for example, specialized food-storing species have been found to perform more accurately than less specialized food-storing species on several spatial memory tests. These tests include food cache recovery (Balda \& Kamil, 1989), an open-field analogue of a radial arm maze (Kamil, Balda, \& Olson, 1994), and an operant delayed matchingto-sample task (Olson, 1991). The size of the avian hippocampus, which is critical for spatial memory performance in birds (Sherry \& Vaccarino, 1989), is larger in

\footnotetext{
These experiments were undertaken by M.L.P. in partial fulfillment of the requirements for the $\mathrm{PhD}$ in physical anthropology at the University of Pennsylvania. This research was supported by National Science Foundation Dissertation Improvement Grant DBS 92-23912 to M.L.P., NSF grant IBN 92-09528 to J.A.F., and the generosity of E. J, and R. C. L. Brannon. We thank A. C. Kamil for advice on experimental design and D. L. Cheney, P. W. Glimcher, R. S. O. Harding, and R. M. Seyfarth for their valuable comments on the manuscript. D. M. Hightower provided excellent care for the monkeys. Correspondence concerning this article should be addressed to M. L. Platt, Center for Neural Science, New York University, 4 Washington Place, Room 911 , New York, NY 10003 (e-mail: mplatt@cns.nyu.edu).
}

food-storing than in non-food-storing passerine species (Krebs, Sherry, Healy, Perry, \& Vaccarino, 1989), suggesting that differences in the size of the hippocampus may underlie the differences in spatial memory found among Corvid species.

Spatial learning and memory performance also varies with sex-specific patterns of ranging among some species of rodents. For example, in the polygynous meadow vole (Microtus pennsylvanicus), males expand their ranges during the breeding season to encompass the smaller home ranges of multiple females, whereas in monogamous pine voles ( $M$. pinetorum), male and female pairs jointly occupy single home ranges (Gaulin \& Fitzgerald, 1989). When compared on laboratory tests of spatial learning ability, males outperformed females in the polygynous species but not in the monogamous species (Gaulin \& Fitzgerald, 1989). The hippocampus, known to be important for spatial memory and navigation in mammals (O'Keefe \& Nadel, 1978; Squire, 1992), is larger in males than in females among meadow voles but not among pine voles (Jacobs, Gaulin, Sherry, \& Hoffman, 1990).

We present here a preliminary attempt to extend an adaptive, ecologically based framework to the comparative analysis of visuospatial memory in primates. Golden lion tamarins (Leontopithecus rosalia) and Wied's blacktufted-ear marmosets (Callithrix kuhli) were selected for 
study, because they differ significantly in spatial and temporal aspects of foraging in the wild (Sussman \& Kinzey, 1984). Although the diets of these species overlap considerably, with both species feeding predominately on fruits and insects and to a lesser extent on gums, seeds, and flowers (Peres, 1989a, 1989b; Rylands, 1989), there are important differences between their feeding ecologies (Sussman \& Kinzey, 1984). These differences contribute to spatially and temporally divergent ranging behaviors, which may involve different memory specializations.

Morphological specializations of the anterior dentition (Garber, 1992; Sussman \& Kinzey, 1984) enable marmosets, including C. kuhli (Rylands, 1989), to harvest tree gums by gouging. Moreover, marmosets possess an enlarged caecum, which may contribute to efficient gum digestion (Ferrari \& Martins, 1989). Rylands (1989) reported that exudates made up more than $30 \%$ of the plant diet of C. kuhli studied in the Atlantic coastal forest of Brazil. Tree gums renew relatively rapidly, some in hours or minutes (Fonseca \& Lacher, 1984), and Wied's marmosets usually confine their foraging to a small core area (ca. 10 ha) containing one or a few gum trees, to which they may return to feed up to three times per day (Rylands, 1989).

These dental adaptations, however, are at most incipient in golden lion tamarins (Garber, 1992; Sussman \& Kinzey, 1984). Although golden lion tamarins are known on occasion (1.5\% of feeding records: Peres, $1989 \mathrm{~b}$ ) to actively gouge trees for gum in the dry season, they feed predominately on small animal prey (especially insects) and fruits, nectar, and other plant reproductive parts (Rylands, 1989; Sussman \& Kinzey, 1984). Fruits, flowers, and seeds, as well as their insect prey, occur in widely distributed patches, and golden lion tamarins traverse a relatively large home range as they feed on these foods (ca. 36-48 ha: Dietz \& Baker, 1993; Peres, 1989a). Moreover, these tamarins spend more time feeding on fruit in the center and periphery of their range than in intervening areas; thus their principle plant resources are relatively widely separated in space (Peres, 1989a). When golden lion tamarins were observed to actively harvest gums, they returned to the same liana (Machaerium sp.) once every 3 days over a 2-week period (Peres, 1989b).

In order to make efficient use of widely separated, ephemeral patches of ripe fruit and insect foraging sites distributed over a relatively large home range, golden lion tamarins may require enhanced spatial memory and navigational ability (cf. Clutton-Brock \& Harvey, 1980; Milton, 1981). Marmosets, however, may use spatial memory to return to particular closely spaced gum-feeding sites (which number in the hundreds on any one tree: Sussman \& Kinzey, 1984) over relatively short time intervals. The possibility thus exists that the observed differences in feeding ecology in these otherwise similar species may be correlated with differences in the ability of these animals to retain and use information about the location of food over different time intervals. Wied's marmosets, for example, might be expected to remember spatial information equally or more accurately than golden lion tamarins after short retention intervals, but as the retention interval is increased, golden lion tamarins might be expected to remember spatial information more accurately than would Wied's marmosets.

We report here species differences in performance on several memory tasks that varied with retention interval. The marmosets outperformed the tamarins after a 5-min retention interval on an open-field analogue of a radial arm maze and on an open-field analogue of a spatial delayed matching-to-sample task. As the retention interval was increased to $24 \mathrm{~h}$ in the radial arm maze analogue, and to $48 \mathrm{~h}$ in the spatial delayed matching-to-sample analogue, the tamarins outperformed the marmosets. In a third experiment, the marmosets learned to match the color of a rewarded feeder irrespective of location in fewer trials than did the tamarins when the retention interval was $5 \mathrm{~min}$. However, when the retention interval was increased to $24 \mathrm{~h}$, the tamarins performed more accurately than the marmosets. Because the differences in performance were consistent across different tasks that required different response strategies, we argue that they reflect adaptive differences in memory rather than the propensity for each species to adopt a particular response strategy that would be appropriate for one task but not others.

\section{EXPERIMENT 1}

\section{Method}

\section{Subjects}

Three adult golden lion tamarins ( 2 males and 1 female) and 3 adult Wied's marmosets ( 1 male and 2 females) served as subjects in this experiment. All 6 subjects were naive to the task at the beginning of testing. The subjects were maintained at the University of Nebraska at Omaha Callitrichid Research Center. They were housed in cages measuring $1 \times 2 \times 2.7 \mathrm{~m}$ (high) or $1 \times 1 \times$ $2.33 \mathrm{~m}$ (high). The monkeys were fed a morning meal consisting of ZuPreem Marmoset Diet, a high protein food (e.g., eggs, cheese), and bread and an afternoon meal consisting of fresh fruit. Lighting was controlled automatically by a timer set for a $12: 12-\mathrm{h}$ light:dark cycle.

\section{Apparatus}

Testing was conducted in an open-field analogue of a radial arm maze. Small opaque plastic cups $(6 \mathrm{~cm}$ in diameter, $5 \mathrm{~cm}$ deep) painted bright yellow served as feeders and were mounted at eight locations on the walls of the $2 \times 2 \times 2.7 \mathrm{~m}$ (high) cage, $1 \mathrm{~m}$ apart and $2 \mathrm{~m}$ high. Thus, four feeders were located in the corners, and four feeders were located midway between corners. Natural branches connected each of the feeders to the center of the arena, thus acting as analogues of the arms of the traditional radial maze apparatus. During testing, yellow adhesive Post-It Notes (3M Corporation), measuring $7.5 \times 7.5 \mathrm{~cm}$, or tight-fitting plastic lids concealed the contents of the feeders. The room was illuminated by two fluorescent light fixtures, and a small incandescent light was hung over the portal through which the monkeys entered and exited the experimental arena. Landmarks in the room included the door to the room with its semi-opaque window, the front and rear entrance doors to the experimental cage, the monkey entrance/ exit portal, and a chair placed in one corner, as well as differences in the size, shape, and texture of branches leading to each feeder.

\section{Procedure}

Pretraining. Before testing began, subjects were first pretrained to remove Post-It Notes from feeders. This was accom- 
plished by placing an uncovered feeder in a subject's home cage and baiting it with some food. Different foods were effective rewards for each species. Golden lion tamarins were rewarded with raisins. Wied's marmosets received frozen mealworms (Tenebrio) as rewards. Once the subject had removed and consumed the food, the feeder was hung at a different location and rebaited. After the subject had learned to find food in the feeder, the feeder was gradually covered with a Post-It Note until the subject pulled the PostIt Note from a completely covered feeder to obtain the hidden food.

Training. The subjects were trained to find food in the experimental arena. A subject was first held in its nest box before it was awakened at about 6:00 a.m. by the remote release of a swinging door. The subject was then transferred to a small transport cage in which it waited until being carried to the experimental room for the start of its trial. The subject entered the experimental apparatus via a small portal fitted with a guillotine door. The subject was then allowed to forage freely among all eight feeders until it collected all the rewards or until $30 \mathrm{~min}$ had elapsed. After the end of this foraging period, the light above the entry/exit portal was turned on, the overhead lights were turned out, and a piece of food reward was placed inside the transport cage. The experimenter then raised the guillotine door and waited for the subject to go into the transport cage. Once inside the transport cage, the subject was taken back to its home cage. Training continued until each subject collected all eight rewards and returned to the transport cage within 15 min. All 6 subjects completed training within 5 trials. After successful training, subjects entered the testing stage of the experiment.

Testing. Testing followed a forced-choice format, divided into two phases: preretention (forced choice) and postretention (free choice). The preretention and postretention phases were separated by a retention interval - a period of lights out during which the subject could not forage (except during the 24 -h retention interval; see below). Before the start of each trial, all eight feeders were baited with a reward. Four randomly selected locations were then covered with Post-It Notes while the other four feeders were made unavailable by capping them with tight-fitting lids. The preretention phase then began, and a single subject was allowed into the test chamber to forage among the available feeders. A visit was scored whenever the subject deliberately removed the Post-It Note covering a feeder with its hand or mouth; if the subject happened to knock off a Post-It Note with its tail in passing or if a Post-It Note otherwise fell off, a visit was not scored. Return visits to previously visited feeders were not scored, because these feeders were visually distinctive by virtue of their not being covered with Post-It Notes and thus could be avoided by the subject without the aid of memory. The experimenter recorded the location and time of visits and the elapsed time. In addition, the experimenter recorded all instances of scent marking. If the subject failed to visit all four available feeders within $15 \mathrm{~min}$ on the preretention phase, the trial was aborted and a make-up trial scheduled.

Immediately after the subject visited all four available feeders, the retention interval began. Removing subjects from the test arena during the retention interval proved difficult. Therefore, for the 5 - and $30-$ min retention intervals, the subjects remained in the test arena for the duration of the retention interval with the lights off, which prevented foraging. The subjects were returned to their home cages, and their pairmates, for the 24-h retention interval. With the lights off, the experimenter entered the test chamber with a small flashlight, removed the Post-It Notes from the floor, opened the four remaining feeders (which still contained food), and rapidly covered all eight feeders with message notes. The subjects typically maintained a maximum distance from the experimenter throughout this procedure. The experimenter then left the experimental room, leaving the overhead lights off. After the retention interval, the lights were turned back on, and the subject was allowed to forage among all eight feeders until it visited all four baited feeders. If a subject failed to visit four feeders within $15 \mathrm{~min}$, the trial was discarded, and a replacement trial was scheduled for another day.

Testing was conducted immediately after lights on in the morning, after the typical overnight fast and before the morning feeding. We tested subjects 7 days per week, with one trial per subject conducted each day. Intertrial intervals were thus $24 \mathrm{~h}$ long for the 5 - and 30 -min retention interval testing, and they were $48 \mathrm{~h}$ long for the 24-h retention interval testing. To examine acquisition of the task, we conducted 10 trials for each subject with a 5-min retention interval interposed between preretention and postretention. Next, we tested performance after three retention intervals: $5 \mathrm{~min}, 30 \mathrm{~min}$, and $24 \mathrm{~h}$. Retention intervals were presented in random order. Each subject was tested on five trials at each retention interval.

\section{Acquisition}

We used the proportion of correct choices through the fourth visit on the postretention phase of trials as the basic measure of performance. Both species outperformed the chance expectation of $50 \%$ correct. The tamarins averaged $60 \%$ correct $(S E=3 \%)$, whereas the marmosets averaged $82.5 \%(S E=4 \%)$. The marmosets performed significantly better than the tamarins $[F(1,4)=$ $12.15, p<.05]$. There was no effect of practice when the first block of five trials was compared with the second block of five trials $[F(1,4)=0.06$, n.s. $]$, and there was no interaction between species and block $[F(1,4)=1.56$, n.s.]. Subjects were never observed to scent-mark feeders or branches leading to feeders, atthough they occasionally scent-marked the branch leading to the exit portal. Subjects typically moved rapidly between feeders, pausing only to consume the food reward.

We also analyzed performance as a function of the temporal sequence of visits. Both species scored better than $80 \%$ correct on the first visit. On subsequent visits, however, the marmosets continued to perform at a high level, whereas the performance of the tamarins declined markedly. This difference between the two species also was significant $[F(1,4)=11.655, p<.05]$.

We also analyzed the serial position of errors. The marmosets made more erroneous postretention visits to the feeder visited first on the preretention phase of the trial than to the other three feeders $\left[\chi^{2}(3)=19.72, p<\right.$ $.001]$. Balda and Kamil (1988) reported a similar "reverse primacy" effect for Clark's nutcrackers. They suggested that subjects might prefer a particular feeder and choose it first whenever possible, thereby depressing performance on the first choice. When the frequencies of first choice of each feeder during preretention were compared with chance performance, none of the marmosets showed a strong preference for any one of the feeders. This suggests that the reverse primacy effect for marmosets reflects a decay of memory for feeder locations visited earlier in the trial, rather than a behavioral bias. The tamarins, in contrast, did not show a reverse primacy effect or a bias for any particular feeder locations. Neither species biased errors toward feeders located next to correct ones. Thus, they did not generalize spatially among feeders (Olton \& Samuelson, 1976). 


\section{Retention Test}

When tested with different retention intervals, the tamarins outperformed chance at all three retention intervals, whereas the marmosets outperformed chance after delays of 5 and $30 \mathrm{~min}$, but not $24 \mathrm{~h}$ (Figure 1). There was a significant effect of retention interval $[F(2,8)=$ $38.390, p<.01]$ and a significant interaction between species and retention interval $[F(2,8)=16.439, p<.01]$. A Newman-Keuls post hoc test revealed significant $(p<$ .01 ) differences between species at $5 \mathrm{~min}$ and $24 \mathrm{~h}$. The tamarins performed worse than the marmosets at $5 \mathrm{~min}$, whereas they performed better than the marmosets at $24 \mathrm{~h}$. No significant differences were found between the last block of 5 trials during acquisition and the 5 trials at the 5-min retention interval during retention testing [lion tamarin, $t(4)=-0.625, p>.25 ;$ marmoset, $t(4)=-2$, $p>.05]$; thus, performance did not change between the two experimental phases. In contrast with that of other species (e.g., titmice; Hilton \& Krebs, 1990), performance did not decline significantly across successive visits $[F(3,12)=1.668$, n.s. $]$.

The time taken by subjects to collect all four food rewards on the postretention phase of trials was examined because we believed that it provided an index of motivation to perform. There was no effect of species $[F(1,4)=$ 0.014 , n.s.] or retention interval $[F(2,8)=1.797$, n.s. $]$, nor was there an interaction between species and retention interval $[F(2,8)=3.053$, n.s. $]$. The speed of food recovery varied little between treatments, and therefore probably did not contribute to differential performance.

Analysis of the serial position of errors indicated that, as during acquisition, the marmosets showed a reverse primacy effect: at retention intervals of 5 and $30 \mathrm{~min}$, they directed more errors toward the feeders visited first or

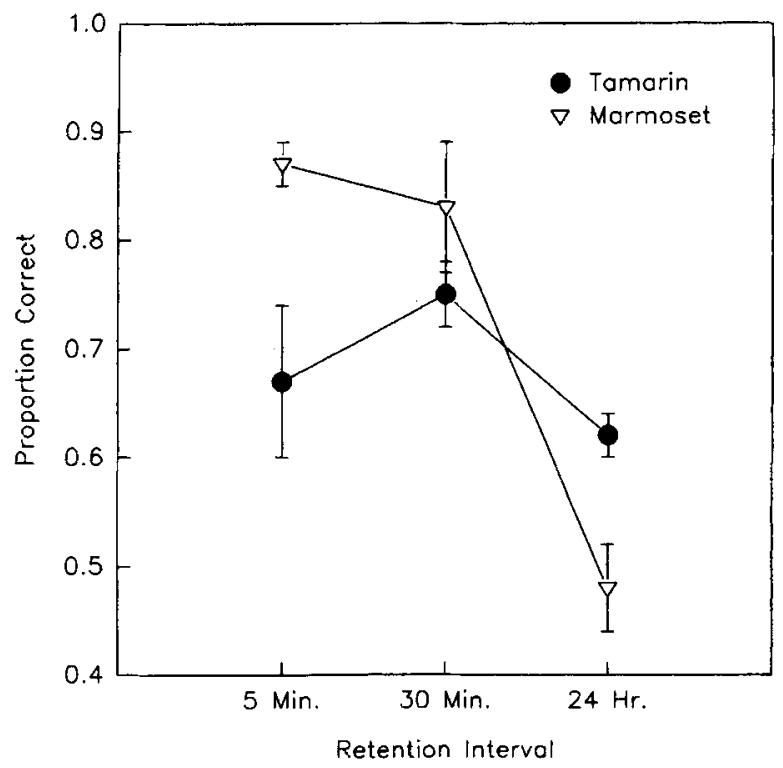

Figure 1. Mean proportion correct during the first four visits after three retention intervals in Experiment 1 (bars indicate $\pm S E$ ). second on the preretention phase of a trial than to those visited third or fourth $\left(\chi^{2}=33.88\right.$ and $40.93, p s<.001$, respectively). The marmosets did not, however, show any serial position effects on errors made after $24 \mathrm{~h}$. As during acquisition, the tamarins did not display any serial position effects at any retention interval. Again, neither species biased errors toward feeders located next to correct ones.

\section{Discussion}

Marmosets and tamarins performed differently on our open-field analogue of a radial arm maze at different retention intervals. These performance differences were consistent with predictions derived from differences in feeding and ranging behavior in the wild. Marmosets return up to three times a day to frequently renewing food sources within a relatively small home range, whereas tamarins return only after days or weeks to more widely distributed sources of food. These differences in performance, however, must be interpreted with caution, because differences in sensory physiology, motor abilities, or motivation may contribute to species differences in performance on any single task in the absence of any real differences in learning or memory ability (MacPhail, 1982).

Despite this general limitation, other radial maze studies have reported adaptive variation in performance among bird taxa. For example, Hilton and Krebs (1990) found that food-storing bird species of the family Paridae performed better than chance after a 24-h retention interval, whereas non-food-storing species did not. Similarly, Kamil et al. (1994) found species differences in acquisition, accuracy, and retention among food-storing bird species of the family Corvidae that correlated with morphological specializations for carrying seeds and level of dependence on stored food in the wild.

Like rats (Olton \& Samuelson, 1976), pigeons (Spetch \& Edwards, 1986), and Clark's nutcrackers (Balda \& Kamil, 1988), marmosets and tamarins did not make more errors to feeders located next to correct feeders. Staddon (1983) has suggested that such a lack of "spatial generalization" of errors reflects the use of a temporal, rather than spatial, code to represent the status, either visited or unvisited, of known feeder locations. According to this model, memory traces for feeder locations visited on the current trial would be stronger than those visited on previous trials, and subjects could use this difference in memory trace strength to discriminate rewarded from unrewarded feeders. In addition, like rats, the marmosets tended to distribute more errors to feeders visited earliest on the preretention phase of trials. Staddon (1983) has suggested that this type of recency effect reflects the decay of memory for feeders visited earlier on the trial relative to those visited later. Because their principal food sources in the wild renew within hours, rapid memory decay could be viewed as an adaptive specialization of marmoset foraging behavior that enables them to avoid proactive interference.

The tamarins, however, did not exhibit systematic serial position errors on our radial arm maze task. One pos- 
sible explanation for this pattern of performance is that the tamarins may have forgotten the location of previously visited feeders less rapidly than the marmosets. Such slowly decaying memory traces might contribute to proactive interference of information from previous trials if the intertrial interval is short (Staddon 1983, 1985); proactive interference might account for the relatively poor performance of the tamarins at short retention, and hence intertrial, intervals.

\section{EXPERIMENT 2}

In the radial arm maze task, subjects must avoid returning to previously visited locations (a win-shift strategy). Because marmosets tend to return to particular food sources (a win-stay strategy) within $24 \mathrm{~h}$ in the wild, they may have found it difficult to adopt a win-shift strategy after a 24-h retention interval on our radial arm maze task. Thus, the species differences in performance we found after $24 \mathrm{~h}$ in Experiment 1 may be due to differences in response strategy rather than differences in memory (Olson, Kamil, \& Balda, 1993). To address this issue, we compared these two species on an open-field task similar to a spatial delayed matching-to-sample task. In this task, subjects were required to return to specific feeder locations after a retention interval. Thus, if differences in performance on the radial maze task were due to the inability of marmosets to adopt a win-shift response strategy after a $24-\mathrm{h}$ retention interval, then no species differences should be found when the task requires a win-stay strategy. Species differences on this second task, however, would suggest that performance differences on both tasks reflect different learning and memory abilities rather than species-specific response strategies.

\section{Method}

\section{Subjects}

Six adult tamarins and 6 adult marmosets served as subjects for this study. All 12 subjects were naive to the task at the beginning of the study. Housing and maintenance were as described for Experiment 1 .

\begin{abstract}
Apparatus
All training and testing were conducted in the subjects' home cages. Each cage was roughly similar in size and constructed from the same materials. On one wall of each cage, five feeding sites were arranged in an "X." The four corner sites were separated by $.75 \mathrm{~m}$, while the middle site was located at the intersection of the diagonals connecting the other four. The array itself was elevated $1.2 \mathrm{~m}$ off the floor. During testing, yellow plastic feeders covered with Post-It Notes were hung at each of the five locations. Two sets of feeders were used, one for preretention and one for postretention, in order to make the use of any scent marks left by the animals on the feeders unrewarding. Natural branches inside the cage provided support for locomotion and foraging. During testing, the animals were separated from their cagemates by a wire divider.
\end{abstract}

\section{Procedure}

Pretraining. The subjects were pretrained to remove Post-It Notes from feeders to obtain food as in Experiment 1. The tamarins were reinforced with raisins. The marmosets were reinforced with small pieces of marshmallow. All subjects completed pretraining within 3 days.

Training. Training consisted of two stages. During Stage 1, the experimenter first separated the subject from its cagemate by a wire divider. Then the experimenter filled each of five feeders with one reinforcer, covered them with Post-It Notes, and then hung the feeders in the marked sites in the subject's cage. The experimenter then exited the cage and started a stopwatch. The subject was free to forage among the five feeders. A visit was scored whenever the subject removed the Post-It Note from a feeder with its hand or mouth, or reached under the Post-It Note to explore the feeder manually. The experimenter recorded the location and time of each visit. When a subject visited all five feeders within $5 \mathrm{~min}$ on a single Stage 1 training trial, it entered the second stage of training.

Stage 2 training trials were divided into two phases: preretention and postretention. The subject was first separated from its cagemate by means of a wire divider. Then one randomly determined location was fitted with a baited feeder while unbaited feeders were hung in the other four locations. Post-It Notes covered all five feeders. After the experimenter had hung up all five feeders and exited the cage, the preretention phase began, and the subject was free to forage among the five feeders. The experimenter recorded the time and location of visits and all instances of scent marking. Immediately after the subject visited the baited feeder and consumed the reward, the five feeders were removed from the test cage. The 5 -min retention interval then began. During the retention interval, the experimenter left the room and arranged for the same location to be fitted with a baited feeder while the other four feeders remained unbaited. On the postretention phase of trials, the baited feeders contained three reinforcers instead of one. After the retention interval, the feeders were replaced. The postretention phase then began, and the subject's task was to return to the location where it had found food on the preretention phase of the trial. Training continued until the subject visited the baited feeder within 5 min on each phase of one Stage 2 training trial. During training and testing phases, feeders were always randomly reassigned to locations on the marked array in order to make any scent marks placed by the monkeys on the preretention phase an unreliable guide to the location of food after the retention interval.

Testing. Testing followed the same two-part format as did training. For each subject, the five locations were sampled randomly without replacement until all five had served as the baited location within one five-trial block. If the subject failed to visit the baited feeder on either the preretention or the postretention phase within 5 min of any test trial, the trial was aborted and the intertrial interval restarted. Trials were conducted once daily, 7 days per week.

First, we examined acquisition by conducting 25 trials for each subject with a 5 -min retention interval. Locations within the marked array were sampled randomly without replacement until all five locations had been rewarded once during each of five fivetrial blocks. Next, we examined the effects of retention interval on performance. Ten trials were conducted at each of three retention intervals: $5 \mathrm{~min}, 30 \mathrm{~min}$, and $24 \mathrm{~h}$. Retention intervals were presented in randomized blocks of six trials, so that each retention interval was tested twice within each block. For each retention interval, locations to be rewarded were sampled without replacement until each location had been tested twice at each retention interval. Finally, we tested performance after a 48 -h retention interval. The $48-\mathrm{h}$ retention interval imposed a $72-\mathrm{h}$ intertrial interval on testing. Ten trials were conducted for each individual. One individual of each species was not tested at $48 \mathrm{~h}$.

\section{Results}

\section{Acquisition}

The number of visits taken to find the reward on the postretention phase of trials was used as the measure of performance. The mean number of visits expected on the 
basis of chance is 3 , because each number of visits $(1,2$, 3,4 , and 5) would be expected to occur equally often if locations were sampled without replacement (Brodbeck, Burack, \& Shettleworth, 1992; Healy \& Krebs, 1992a). On the average, the marmosets took fewer visits $(2.38$; $S E=0.09)$ than did the tamarins $(2.59 ; S E=0.09)$ to find the correct feeder. Both species performed significantly better than chance (single-sample $t$ tests, $p s<.01$ ). To examine the effects of species and experience on performance, the number of visits to find the reward on the postretention phase of trials was analyzed with a twofactor mixed analysis of variance (ANOVA). No significant differences were found between species $[F(1,10)=$ 1.887 , n.s.]. The effect of block was also not significant $[F(4,20)=0.400$, n.s. $]$, indicating that performance did not improve with experience.

To test indirectly whether the monkeys used olfactory cues emanating from the hidden food, we examined the number of visits made to find the food reward during the preretention phase of trials. If the monkeys used olfactory cues, their performance on the preretention phase should have been better than chance. Neither species performed better than chance on the preretention phase of trials (single-sample $t$ test, $p$ s $>.1$ ). The tamarins averaged $3.10(S E=0.11)$ visits; the marmosets averaged $3.06(S E=0.10)$; a mean of 3.0 visits would be expected by chance. When the mean number of visits taken by each monkey to find the baited feeder on the preretention phase was compared with the number of visits taken on the postretention phase, a significant effect of phase was found $[F(1,10)=67.82, p<.001]$, but there was no effect of species $[F(1,10)=0.91$, n.s. $]$ or interaction between phase and species $[F(1,10)=1.48$, n.s.]. Both species took fewer visits to find the rewarded feeder on the postretention phase of trials than on the preretention phase, suggesting that subjects initially foraged at random and then returned to the baited feeder location by using memory.

\section{Retention Test}

During retention testing, the marmosets performed significantly better than chance at all three retention intervals, whereas the tamarins performed significantly better than chance at retention intervals of $30 \mathrm{~min}$ and $24 \mathrm{~h}$ (single-sample $t$ test, $p<.05$ ). Performance at $5 \mathrm{~min}$ in this experiment was compared with mean performance during acquisition, and no differences in performance were found (paired $t$ tests, n.s.). Thus, performance levels remained stable throughout the experiment. However, no significant differences were found between species $[F(1,10)=1.07$, n.s. $]$ or retention intervals $[F(2,20)=$ 1.25, n.s.], nor was there an interaction between species and retention interval $[F(2,20)=.67$, n.s.].

When the retention interval was increased to $48 \mathrm{~h}$, the tamarins made an average of 2.66 visits $(S E=0.19)$ to find the reward. The marmosets, on the other hand, made an average of 3.14 ( $S E=0.19$ ) visits to find the reward, a decline to chance. The probability that performance differed between the two species by chance alone was less

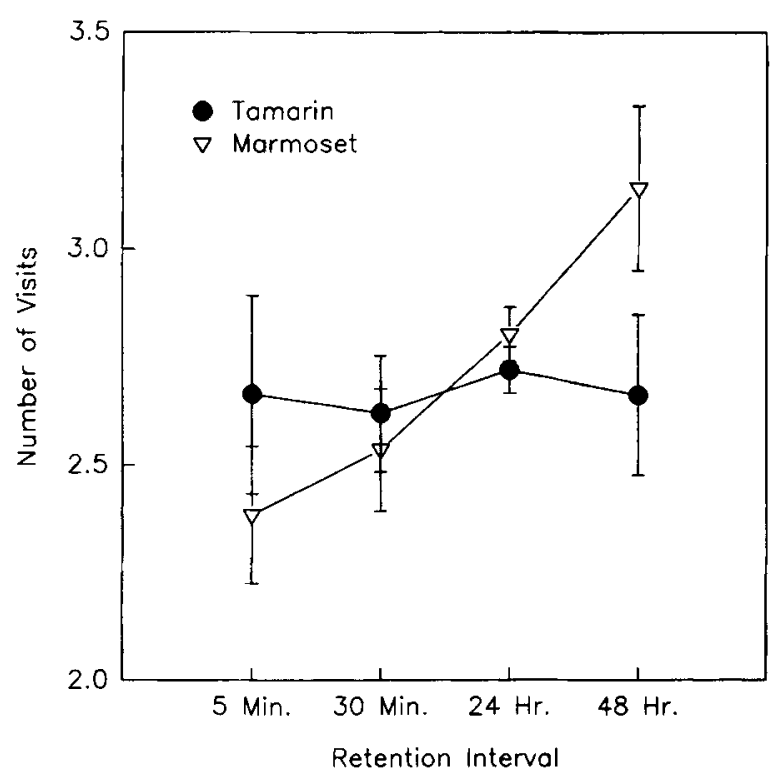

Figure 2. Mean number of visits taken to find the correct, baited feeder after four retention intervals in Experiment 2 (bars indicate $\pm S E$ ).

than $7.5 \%$ (Mann-Whitney test, $U=5, n_{1}=n_{2}=5$ ). When plotted with the data from the 5-min, 30-min, and 24-h retention intervals (Figure 2 ), the performance of the marmosets clearly declined as retention interval increased, whereas the performance of the tamarins remained stable.

\section{Discussion}

In contrast with their performance on our radial arm maze task, the marmosets outperformed chance after a 24-h retention interval in our open-field analogue of a spatial delayed matching-to-sample task. Thus, marmosets can remember information about the spatial location of food for $24 \mathrm{~h}$ in a win-stay task. However, their performance declined to chance after a 48-h delay. Although they performed better than the tamarins after a 5-min retention interval, the marmosets performed worse after longer delays, particularly $48 \mathrm{~h}$. The tamarins performed at similar levels across all retention intervals. These results are consistent with those from our radial arm maze analogue and suggest that response strategy alone cannot account for differences in performance between these two species on our visuospatial memory tasks. Instead, we argue that the performance differences reflect adaptive differences in memory suited to the foraging strategies of each species.

\section{EXPERIMENT 3}

In this experiment, we tested whether differences in performance could be extended to memory for nonspatial visual information that could be used to find food. Our goal was to investigate whether performance differ- 
ences between these two species reflect a specialization of spatial memory itself or a more generalized memory system. We used a win-stay task similar to the task used in Experiment 2 and more closely analogous to a delayed matching-to-sample task. The color of feeders, irrespective of location, served as the relevant cue. Thus, subjects were rewarded for returning to a feeder of the same color as the one baited on the preretention phase of each trial, regardless of where either feeder was located.

\section{Method}

\section{Subjects}

Seven individuals of each species served as subjects for this experiment. All 7 lion tamarins and 6 of the marmosets had participated in previous spatial memory experiments. Housing and maintenance were as described for the previous experiments.

\section{Apparatus}

All training and testing was conducted in the subjects' home cages, as in Experiment 2. However, five plastic cups painted bright colors of different hues (red, yellow, blue, black, and white) served as feeders (Callitrichids discriminate colors from the spectrum visible to humans: Savage, Dronzek, \& Snowdon, 1987). Matching pieces of laminated colored construction paper $(5 \times$ $5 \mathrm{~cm}$ ) served as lids to conceal the contents of the colored feeders. Both species were tested with the same pool of five different colored feeders.

\section{Procedure}

Pretraining. Three days before the beginning of training, the subjects were pretrained to remove the colored lids from feeders to obtain concealed food as described for previous experiments. The lion tamarins were reinforced with raisins, whereas the marmosets were reinforced with small bits of marshmallow. All 14 monkeys were pretrained in less than three days.

Training. After completing pretraining, the subjects began the training phase of the experiment, which consisted of two stages. Stage 1 was as described for Experiment 1 . After a subject had visited all five feeders within 5 min on a single Stage 1 training trial, it entered the second stage of training. Stage 2 training trials were divided into two phases: preretention and postretention. The subject was first separated from its cagemate by means of a wire divider. Then one randomly determined feeder was baited, covered with a lid matching the color of the feeder, and hung in the center location of the marked array. This feeder served as the sample. The experimenter then exited the cage, the preretention phase began, and the subject was free to forage. The experimenter recorded the elapsed time to visit the single baited feeder. Rewarded feeders were sampled without replacement from among the available five feeders until all five different colors had been used.

Immediately after the subject visited the baited feeder and consumed the reward, the experimenter started the 5-min retention interval timer and removed the feeder. The experimenter then left the room and rebaited the same colored feeder rewarded on the preretention phase. The other four feeders remained unbaited, and all five feeders were covered with matching colored lids.

Upon termination of the retention interval, the experimenter entered the cage and hung the feeders in randomly determined locations among the marked array. The postretention phase then began, and the subject's task was to return to the colored feeder in which it had found food on the preretention phase of the trial, irrespective of its current location. The experimenter recorded the location, color, and elapsed time of visits.

Stage 2 training trials were conducted 5 days per week at $1400 \mathrm{~h}$ (lights on at $0630 \mathrm{~h}$ ). Stage 2 training continued until a subject had completed at least 25 , but no more than 50, Stage 2 training trials and had taken an average of 2.8 or fewer visits to find the rewarded feeder on the postretention phase of two consecutive blocks of 5 Stage 2 training trials. The mean number of visits expected if choosing at random was 3 , so fewer than 2.8 visits would suggest better than chance performance. If a subject failed to complete either the preretention or the postretention phase of a Stage 2 training trial within $5 \mathrm{~min}$, the trial was aborted, and a make-up trial was scheduled for another day.

Testing. The testing trials followed the same two-phase format as did the training trials. For each subject, the five colored feeders were sampled randomly without replacement until all five had served as the baited feeder in each sequence of five trials. Feederlocation combinations were determined randomly for each phase of each trial. Performance after three different retention intervals was tested during this experiment: $5 \mathrm{~min}, 30 \mathrm{~min}$, and $24 \mathrm{~h}$. Retention intervals were presented in random order within blocks of six trials. Each retention interval was tested twice within each block. Five blocks of six trials were thus presented to each subject, for a total of 10 trials at each retention interval. Testing was conducted at $1400 \mathrm{~h}$, after the monkeys had been deprived of their afternoon fruit for $3 \mathrm{~h}$. Failure to complete either the preretention or postretention phase resulted in an aborted trial, and a make-up trial was scheduled for the end of the block.

\section{Results}

Five out of 7 tamarins and 5 out of 7 marmosets successfully completed training. The tamarins required an average of $6.4(S E=0.68)$ blocks to reach criterion, whereas the marmosets required an average of $5.6(S E=0.40)$ blocks to reach criterion $[t(8)=1.02$, n.s. $]$.

The number of visits made on the postretention phase to find the colored feeder matching the sample presented on the preretention phase served as the basic measure of performance. The chance expectation was an average of 3 visits. During testing, both species performed poorly at retention intervals of 5 and 30 min (Figure 3). At $24 \mathrm{~h}$, however, the tamarins performed significantly better than chance $[t(4)=3.84, p<.02]$, whereas the marmosets did not $[t(4)=.78, p>.45]$. However, there was no significant effect of species $[F(1,8)=1.944$, n.s. $]$ or retention interval $[F(2,16)=2.469$, n.s. $]$, nor was there an interaction between the two main effects $[F(2,16)=$ 1.132, n.s.] on performance.

Another measure of performance is the proportion of trials on which the first visit was correct (Brodbeck et al., 1992). Chance performance would be expected to average .20. According to this measure, both species performed at chance levels at retention intervals of 5 and $30 \mathrm{~min}$. The tamarins, however, performed significantly better than chance after the $24-h$ delay $[t(4)=2.828, p>$ $.05]$; on the average, they visited the correct feeder first on $40 \%$ of trials $(S E=.071)$. The marmosets, in contrast, continued to perform at chance levels at the 24-h retention interval $[t(4)=0.408$, n.s.]. A mixed ANOVA revealed no significant effect of species $[F(1,8)=2.432$, n.s. $]$ or retention interval $[F(2,16)=2.753$, n.s. $]$, nor any interaction between the two main effects $[F(2,16)=$ 2.084 , n.s.]. However, a post hoc $t$ test revealed significant differences in performance with the 24-h delay $[t(8)=2.557, p<.035]$. 


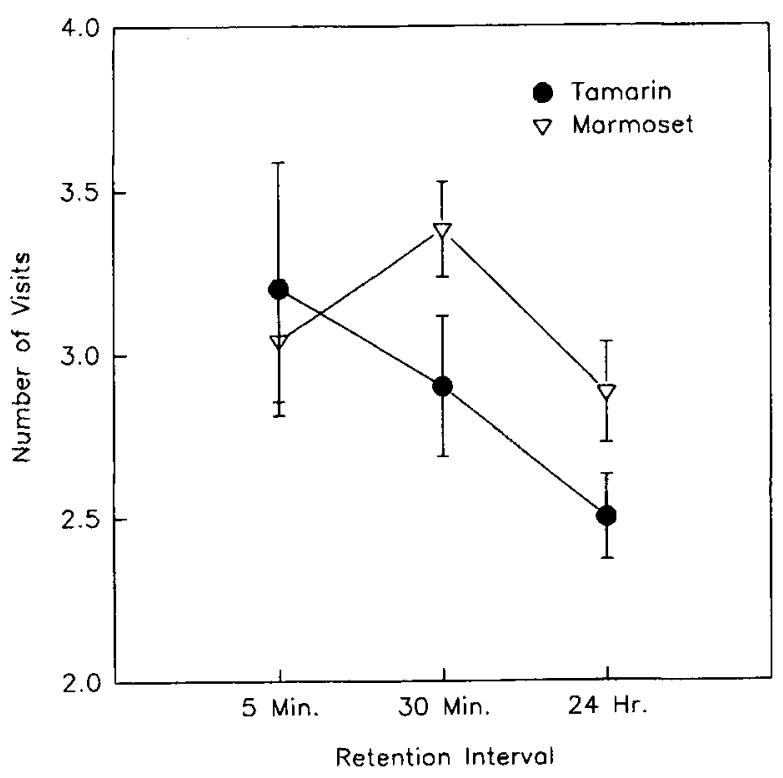

Figure 3. Mean number of visits taken to find the correct, baited feeder after three retention intervals in Experiment 3 (bars indicate $\pm S E$ ).

Both species had difficulty using color as the only available cue to find hidden food. Healy and Krebs (1992b) reported similarly poor performance for titmice tested on a nonspatial matching-to-sample task. Analyses of the spatial distribution of errors revealed that each of the tamarins and each of the marmosets exhibited position biases $\left[\chi^{2}(4)>9.49, p s<.05\right]$. These location biases were less marked for the marmosets than for the tamarins. Subjects may have resorted to a location strategy when their memory for color information failed.

\section{Discussion}

The marmosets learned to perform this color delayed matching-to-sample task to an arbitrary criterion in fewer trials than did the tamarins. When tested after a $24-\mathrm{h}$ retention interval, however, the marmosets performed less accurately than the tamarins and no more accurately than chance. The tamarins, however, outperformed chance with the 24-h delay. These performance differences are consistent with the differences found on both win-shift and win-stay spatial memory tasks in Experiments 1 and 2.

Although both species acquired the task to better than chance levels with a 5-min retention interval, neither species performed better than chance at the same 5-min retention interval when it was presented in randomized blocks with 30-min and 24-h retention intervals. Kamil, Balda, and Olson (1994) have suggested that randomized presentation of retention intervals makes the radial arm maze more difficult, because the retention intervals are unpredictable. A similar deleterious effect of unpredictable retention intervals on performance may have been operative in our color memory experiment.

It is possible that the tamarins performed poorly at short retention intervals in this task because of the intru- sive effects of proactive interference (Staddon, 1983). One would expect much more pronounced effects of proactive interference on the performance of subjects if the intertrial interval was short relative to the time constant of memory trace decay. The $24-\mathrm{h}$ retention interval trials in this task, as in Experiments 1 and 2, effectively doubled the intertrial interval from 24 to $48 \mathrm{~h}$, possibly attenuating proactive interference effects. The poor performance of the tamarins relative to the marmosets at the 5-min retention interval in our radial maze analogue and to a lesser extent in our spatial delayed matching-tosample task would be consistent with this hypothesis.

Color, dissociated from location, seemed to be a cue that was inefficiently employed by both species for solving our delayed matching-to-sample task. In contrast with the rapid, spontaneous acquisition of both spatial memory tasks, both species required extensive training to achieve an arbitrary criterion in this task. Indeed, two individuals of each species failed to achieve the arbitrary performance criterion despite extensive training. It is possible, however, that one reason why acquisition of this task was slow and performance was relatively poor was that testing was conducted in the afternoon, rather than immediately after the overnight fast as in Experiments 1 and 2.

Healy and Krebs (1992b) reported in a study of nonspatial matching-to-sample performance that both foodstoring and non-food-storing titmice never surpassed chance levels even after 50 training trials; instead, the birds adopted position preferences. The tamarins and marmosets also exhibited location biases. In light of this bias, the fact that spatial location was an irrelevant and confounding cue might, in fact, account for the poor performance of these species in this test. It is possible that both tamarins and marmosets use location as the primary source of information for finding food resources and rely on direct visual cues as secondary sources of information.

\section{GENERAL DISCUSSION}

Differences in the spatial and temporal scale of feeding and ranging behavior between golden lion tamarins and Wied's marmosets suggested to us that they might employ differentially specialized memory abilities for foraging. Using a set of tasks that examined visuospatial memory over temporal intervals similar to those confronted by these species in the wild, we found differences in performance that varied with retention interval in a fashion that would be adaptive for animals with these feeding strategies. The marmosets performed better than the tamarins after very short retention intervals $(5 \mathrm{~min})$ on an open-field analogue of a radial arm maze and on an openfield spatial delayed matching-to-sample task. After long (24- or 48-h) retention intervals, however, the tamarins performed better than the marmosets and continued to perform better than chance. Similar differences in performance were found on an open-field color cue matchingto-sample task. The marmosets learned the task in fewer trials than did the tamarins with a 5-min retention inter- 
val. After a $24-\mathrm{h}$ retention interval, however, the tamarins performed better than the marmosets and better than chance. These differences in performance parallel differences in the typical return time to resources in the wild by each species: marmosets usually revisit food sources within $24 \mathrm{~h}$, whereas days or weeks may elapse between visits by tamarins to their widely separated foraging sites.

As other authors have pointed out (Bitterman, 1965; MacPhail, 1982), differences in memory-related performance on a single task can be misleading, because performance reflects the combined effects of learning and memory abilities and the sensory and motor abilities of the subject, its motivation to perform, and the response requirements of the task. In the work presented here, we found consistent differences in performance across tasks. This reduces the possibility that "contextual" (MacPhail, 1982) features alone, such as sensory stimuli, response strategy, or motor requirements, can account for the differential performance of these two species (Kamil, 1988). Although each species was reinforced with a different food, they performed differentially at different retention intervals; reward effectiveness alone cannot explain these differences in memory decay rate.

More research will be necessary, however, in order to clarify precisely which aspects of memory-based performance differ between these species. Performance on these tasks requires attention to relevant stimuli, encoding of memories, retrieval from storage, and correct usage of stored information (Kamil, Balda, \& Olson, 1994). Individual species could differ in any one or more of these processes. Also, more data are needed on the use of visuospatial memory by these species to find food in the wild. For example, Garber (1989) has provided evidence that saddle-back tamarins (Saguinus fuscicollis) and moustached tamarins ( $S$. mystax) may use spatial memory to move linearly between at least 300 separate fruit tree locations in their densely forested home ranges. It would be useful to obtain similar information for these tamarins and marmosets.

Based on these results and a knowledge of the feeding ecology of these two species, our working hypothesis is that Wied's marmosets and golden lion tamarins possess different visuospatial memory abilities that are specialized for tracking the spatiotemporal distribution of their principal foods. Marmosets feed on rapidly renewing gum sources that can be harvested within a relatively small supplying area, as well as insects gleaned opportunistically from nearby foliage. Lion tamarins, in contrast, monitor widely distributed fruit and insect foraging sites that renew over relatively long temporal intervals. Both species possess morphological and behavioral specializations for harvesting their principal foods, and we hypothesize that specialized memory systems are an integral component of these species-specific adaptations for foraging.

In Experiment 3, the tamarins performed poorly when both the retention interval and intertrial interval were relatively short, but when the retention interval was $24 \mathrm{~h}$ and the intertrial interval was $48 \mathrm{~h}$, they performed above chance. These results suggest that their performance may have been hampered by proactive interference from the previous trial. Because they return to food sources only after days or weeks, however, proactive interference would have little effect on their foraging efficiency in the wild. Indeed, slow memory decay would enable lion tamarins to assess the probability of finding food in widely separated foraging sites without daily monitoring, thereby increasing their foraging efficiency. On the other hand, rapid memory decay would permit marmosets to quickly learn new patterns of resource distribution and availability without proactive interference from previous memory traces.

Our hypothesis would be strengthened by the demonstration of neurobiological differences that parallel both the previously demonstrated differences in feeding ecology and this demonstration of differential performance on our visuospatial memory tasks. Differences in hippocampus size similar to those found between food-storing and nonstoring birds (Krebs et al., 1989), for example, would strengthen our hypothesis. Frugivorous primates do possess larger brains for their body size than do folivorous, insectivorous, or gummivorous primates (Clutton-Brock \& Harvey, 1980), and relative neocortical volume varies positively with home range size among primates (Sawaguchi, 1992). A difference between tamarins and marmosets in the size of brain areas devoted to visuospatial memory is thus a distinct possibility. Such differences would suggest that tamarins and marmosets, like corvid birds, possess visuospatial learning and memory systems that are specifically adapted for tracking the spatial and temporal distributions of their primary foods. Moreover, they would raise the possibility that the observed correlation between relative brain size and feeding ecology among extant primates is related, at least in part, to adaptive differences in learning and memory.

\section{REFERENCES}

BALDA, R. P., \& KAMIL, A. C. (1988). The spatial memory of Clark's nutcrackers (Nucifraga columbiana) in an analogue of the radial arm maze. Animal Learning \& Behavior, 16, 116-122.

BALdA, R. P., \& KaMIL, A. C. (1989). A comparative study of cache recovery by three corvid species. Animal Behaviour, 38, 486-495.

Bitterman, M. E. (1965). Phyletic differences in learning. American Psychologist, 20, 396-410.

Brodbeck, D. R., Burack, O. R., \& Shettleworth, S. J. (1992). One-trial associative memory in black-capped chickadees. Journal of Experimental Psychology: Animal Behavior Processes, 18, 12-21.

Clutton-Brock, T. H., \& Harvey, P. H. (1980). Primates, brains and behaviour. Journal of Zoology, 190, 309-323.

Dietz, J. M., \& BAKer, A. J. (1993). Polygyny and female reproductive success in golden lion tamarins, Leontopithecus rosalia. Animal Behaviour, 46, 1067-1078.

FERraRi, S., \& Martins, E. (1992). Gummivory and gut morphology in two sympatric Callitrichids (Callithrix emiliae and Saguinus fuscicollis weddelli) from Western Brazilian Amazonia. American Journal of Physical Anthropology, 88, 97-103.

FonsECA, G. A. DA, \& LACHER, T. E. (1984). Exudate-feeding by Callithrix jacchus penicillata in semideciduous woodland (Cerradao) in Central Brazil. Primates, 25, 441-450.

Garber, P. A. (1989). Role of spatial memory in primate foraging patterns: Saguinus mystax and Saguinus fuscicollis. American Journal of Primatology, 19, 203-216. 
GARBER, P. A. (1992). Vertical clinging, small body size, and the evolution of feeding adaptations in the Callitrichinae. American Journal of Physical Anthropology, 88, 469-482.

Gavlin, S. J. C., \& FitzGerald, R. W. (1989). Sexual selection for spatial-learning ability. Animal Behaviour, 37, 322-331.

Healy, S. D., \& KREBS, J. R. (1992a). Comparing spatial memory in two species of tit: Recalling a single positive location. Animal Learning \& Behavior, 20,121-126.

HeaLy, S. D., \& KREBS, J. R. (1992b). Delayed-matching-to-sample by marsh tits and great tits. Quarterly Journal of Experimental Psychology, 45B, 33-47.

Hilton, S. C., \& KreBs, J. R. (1990). Spatial memory of four species of Parus: Performance in an open-field analogue of a radial maze. Quarterly Journal of Experimental Psychology, 42B, 345-368.

Jacobs, L. F., Gaulin, S. J. C., Sherry, D. F., \& Hoffman, G. E. (1990). Evolution of spatial cognition: Sex-specific patterns of spatial behavior predict hippocampal size. Proceedings of the National Academy of Science, 87, 6349-6352.

KAMIL, A. C. (1988). A synthetic approach to the study of animal intelligence. In D. W. Leger (Ed.), Comparative perspectives in modern psychology: Nebraska Symposium on Motivation (Vol. 35, pp. 230-257). Lincoln: University of Nebraska Press.

Kamil, A. C., Balda, R. P., \& Olson, D. J. (1994). Performance of four seed-caching corvid species in the radial-arm maze analog. Journal of Comparative Psychology, 108, 384-393.

Krebs, J. R., Sherry, D. F., Healy, S., Perry, V., \& Vaccarino, A. (1989). Hippocampal specialization of food-storing birds. Proceedings of the National Academy of Science, 86, 1388-1392.

MACPHAIL, E. M. (1982). Brain and intelligence in vertebrates. Oxford: Oxford University Press, Clarendon Press.

MiLton, K. (1981). Distribution patterns of tropical plant food as an evolutionary stimulus to primate mental development. American Anthropologist, 83, 534-548.

O'KeEFE, J., \& NADEL, L. (1978). The hippocampus as a cognitive map. London: Oxford University Press.

OLSON, D. J. (1991). Species differences in spatial memory among Clark's nutcrackers, scrub jays, and pigeons. Journal of Experimental Psychology: Animal Behavior Processes, 17, 363-376.

Olson, D. J., KamiL, A. C., \& BaLda, R. P. (1993). The effects of response strategy and retention interval on performance of Clark's nutcrackers in a radial maze analogue. Journal of Experimental Psychology: Animal Behavior Processes, 19, 138-148.

Olton, D. S., \& Samuelson, R. J. (1976). Remembrance of places passed: Spatial memory in rats. Journal of Experimental Psychology: Animal Behavior Processes, 2, 97-116.

Peres, C. A. (1989a). Costs and benefits of territorial defense in wild golden lion tamarins, Leontopithecus rosalia. Behavioral Ecology \& Sociobiology, 25, 227-233.

Peres, C. A. (1989b). Exudate-eating by wild golden lion tamarins, Leontopithecus rosalia. Biotropica, 21, 287-288.

RylandS, A. B. (1989). Sympatric Brazilian callitrichids: The black tufted-ear marmoset, Callithrix kuhli, and the golden-headed lion tamarin, Leontopithecus chrysomelas. Journal of Human Evolution, 18, 679-695.

Savage, A., Dronzek, L. A., \& Snowdon, C. T. (1987). Color discrimination by the cotton-top tamarin (Saguinus oedipus oedipus) and its relation to fruit coloration. Folia Primatologica, 49, 57-69.

SaWAGUCHI, T. (1992). The size of the neocortex in relation to ecology and social structure in monkeys and apes. Folia Primatologica, 58, 131-145.

SPETCH, M. L., \& EdWARDS, C. A. (1986). Spatial memory in pigeons (Columbia livia) in an "open field" feeding environment. Journal of Comparative Psychology, 100, 266-278.

SQuire, L. R. (1992). Memory and the hippocampus: A synthesis from findings with rats, monkeys, and humans. Psychological Review, 99, 195-231.

STADDON, J. E. R. (1983). Adaptive behavior and learning. Cambridge: Cambridge University Press.

STADDON, J. E. R. (1985). Interference, memory, and representation. In J. M. Weinberger, J. L. McGaugh, \& G. Lynch (Eds.), Memory systems of the brain: Animal and cognitive processes (pp. 287-295). New York: Guilford.

Sussman, R. W., \& Kinzey, W. G. (1984). The ecological role of the Callitrichidae: A review. American Journal of Physical Anthropology, 64, 419-449.

(Manuscript received June 9, 1995; revision accepted for publication January $17,1996$. 